\title{
An Additive Statistical Modeling Approach to the Analysis of Transport Infrastructure Flood Risk-Based Resilience
}

\author{
Mohammad Mojtahedi, Sidney Newton and \\ Faham Tahmasebinia
}

Additional information is available at the end of the chapter

http://dx.doi.org/10.5772/intechopen.69232

\begin{abstract}
Australia is a very vulnerable region to flood events, and the frequency of flood events and damage has increased dramatically over the past decades. Although flood has impacted diverse types of buildings and built infrastructure, there has been limited research investigating flood risk management specific to transport infrastructure in Australia and the factors that might influence the resilience of the transport infrastructure to flooding. To develop an appropriate design management system for roads and bridges specific to risk assessment from flooding requires a multitude of factors to be identified and analyzed. In this study, we review the range of critical factors necessary to represent the resilience of bridges to extreme flood events and demonstrate a novel mathematical approach to evaluate the relationship between the bridge resilience and flood risk. We use additive statistical approach in arriving at a framework to evaluate the resilience of bridges. The findings confirm that metrological characteristics such as annual exceedance probability and probable maximum precipitation and structural integrity of the bridge represented by the structural age of the bridge and mechanical properties of the soils have a substantial impact on the resilience of the Australian transport infrastructure, particularly bridges located on main roads.
\end{abstract}

Keywords: resilient, risk, flood, transport infrastructure

\section{Introduction}

Like most countries, Australia is hugely susceptible to flood damage. The frequency of extreme flood events in Australia has increased dramatically over the recent years, and the economic 
loss associated with individual flood events has also increased [1]. For example, in 2010/2011, floods in Queensland, Australia, had a devastating impact on almost 10,000 km of road network and $5000 \mathrm{~km}$ of rail network, and severely damaged around 100 significant bridges and culverts, 400 schools, and 150 national parks [2]. In 2013, a localized flood near Brisbane, Australia, damaged 43 of the total 46 bridges in that location. On average, Australia will experience a roughly 300 -fold increase in flooding events by 2100 , meaning that infrastructure that is presently flooded once in 100 years will be flooded several times per year with a modest prediction of sea level rise $(50 \mathrm{~cm})$ [3]. There has been limited research investigating flood damage and flood risk management specific to infrastructure in Australia [4, 5]. However, previous research has tended to focus on building damage, and there has been no previous consideration of flood impact on Australian transport infrastructure and/or the factors that might influence the resilience of the transport infrastructure to flooding [6]. Transport and associated infrastructure such as roads, railways, bridges, warehouses, airports, ports, and tunnels are often exposed to the risk of direct damage from climate events. Transport infrastructure also has a vital role before, during, and after extreme weather events to reduce the vulnerability of the community more generally. Transport infrastructure vulnerability will vary by region, location, elevation, and the underlying condition of the infrastructure [7].

Elevated ocean levels can increase flood levels in the lower reaches of rivers, either by preventing floodwaters from discharging into the ocean or by filling up low-lying land and estuarine flood storage areas before the river flooding arrives. River flooding in the vast flat areas may last for one or more weeks, or even months on some occasions in some regions in Australia and can lead to extensive damage to rural towns, rural and urban roads, and rail networks [8]. In Australia, low-lying coastal areas can be inundated by storm surges, usually caused by tropical cyclones. Overflow of drainage systems in populated urban areas can also be a major problem.

The performance of transportation networks is critical for the economy and society. Maintaining structural reliability and functionality of the network under extreme hazard effects is therefore a key consideration. In any transport network, bridges and culverts are often the most vulnerable elements because of their propensity for catastrophic collapse [3, 7]. The potential economic and social disruptions due to the loss of or damage to transport infrastructure bridges are hugely significant. The possible adverse effects of increased flooding on bridges range from potential catastrophic structural collapse to increased frequency of maintenance required to ensure a minimum level of service [9]. Given that the most common form of flooding in Australia is river flooding [10] and most bridges in Australia are constructed over the rivers, it is essential to identify bridges that may be vulnerable to flood events in order to mitigate the risks associated with extreme weather events most effectively.

Effective flood risk management is aimed at increasing the resilience of transport infrastructure, but needs to balance the costs of mitigation against the benefits offered by increased resilience. Each situation and the specific community values will vary. In a general case, regular account might be taken of the following flood risk management measures for bridges:

1. The potential for and impact of ground liquefaction around bridges.

2. The slope and stability of associated riverbanks. 
3. The structural performance of the bridge itself in standard risk evaluation terms.

4. A benchmark classification of failure probability across high, medium, or low probabilities.

5. A common rating measure applied to each bridge that combines several key factors to assess the vulnerability of the particular bridge structure.

Having an efficient and effective measure for the resilience of individual bridges is important to transport authorities, local councils, and emergency services. Efficiency in terms of data collection and calculation is important because there are a large number of bridges, in continuously varying circumstances, which require constant evaluation and reevaluation in normal service, the aftermath of an event, a near miss, and even following an event elsewhere that impacted a similar bridge. Nowhere is the need for an efficient and effective measure of resilience more pronounced than in the design and design management guidelines for bridges.

To develop or inform an appropriate design management system for bridges specific to risk assessment from natural hazards such as flooding requires a multitude of factors to be identified and analyzed. A recent analysis of the current design standards for bridges highlighted shortcomings specific to the resilience of bridges [11]. However, the more factors considered in design models, the greater the complexity of the design models are and the less practical the guidelines are in interpreting the resilience [12]. A bridge subject to an extreme flood event can be damaged in many different ways. For example, where the structure of a bridge is completely inundated during a flood, the damage to the bridge depends on the length of time it is submerged.

In large part, due to the potential complexities associated with evaluating the resilience and flood risk of a bridge, mathematical evaluation of bridge designs is missing from previous research. In this study, we review the range of critical factors necessary to represent the resilience of bridges to extreme flood events and demonstrate a novel mathematical approach to evaluate the relationship between the bridge resilience and flood risk.

\section{Critical factors for bridge resilience and flood risk}

Bridges are designed to provide an extended period of service and be resilient to particular extreme weather events. There are many and varied factors taken into account in the design of a bridge, including structural system, loading, resistance, exposure, natural environment, soil characteristics, planned maintenance, inspection regime, economic considerations, and various deficiency functions (load capacity, vertical clearance, deck width, etc.) [13]. However, the condition and performance of a bridge will vary over time in response to various environmental changes, actual maintenance practice, and changes in the quantity and magnitude of actual loads applied [12].

According to the Intergovernmental Panel on Climate Change (IPCC), a flood is "the overflowing of the normal confines of the stream or other body of water, or the accumulation of water over areas that are not normally submerged" [3]. Floods occur more often than many other types of natural disasters [14] and are generally regarded as the most catastrophic and 
lethal of all natural disaster types [15]. During the past century, floods have killed something in the order of 8 million people, globally [16]. Approximately 800 million people currently live in flood-prone areas across the world, and almost $10 \%$ of those are exposed to floods on average each year $[17,18]$.

Not all floods are of equal consequence. Leroy [19] states that time, area, and socioeconomic characteristics tend to amplify the impact of natural disasters. Ho et al. [20] show that the type of natural disaster is a good predictor of the scale of damage likely to be incurred as a direct consequence. Merz et al. [21] propose that flood type, the flood-generating process, the region or zone, and frequency are the most important characteristics to consider in predicting the impact of a flood disaster. A comprehensive literature review on flood characteristics and their relationships with flood damage undertaken by Middelmann-Fernandes [22] found that various parameters contribute to bridge damage: the depth of water, flow velocity, duration of inundation, contamination, sediment or debris load, and the age and materials of the bridge itself. A number of studies have also found that flood type, severity, and frequency are the three most useful predictors of the damage caused by flooding [3, 23, 24].

The management of flood risk reduction and flood disaster management bring further factors into consideration [25]:

- The behavior of the flood itself, including the immediate dangers and potential damage caused.

- The broad cost of flooding borne by the community.

- The projected use of the land in the future and possible lost opportunities due to potential for flooding.

- The environmental needs and impact of the source river and related floodplain areas.

- The environmental and cultural impact of mitigation measures.

This expanding scope of factors to consider around flood risk management renders the problem as a massively multidisciplinary issue. It involves high level of skills in planning, engineering, the social and environmental sciences, economics, and emergency management.

In addition to the breadth of skills required, flood risks vary depending on the temporal perspective taken. Perspectives change from a focus on existing risks, to ongoing risks, and future risks. For example, existing risks deal more specifically with the management of flood damage to maintain or return the community, properties, and infrastructure as it currently exists. Future risks deal with the potential for damage to areas not yet, but in the future possibly, developed to become of economic, social, or environmental significance. Ongoing risks target the potential local impact of generally external flood risks, where floods elsewhere might overwhelm the local infrastructure.

Flood types themselves can also vary. Risks are different where the cause of the flooding is a river blockage (fluvial), excess rainwater (pluvial), coastal inundation, lake blockage, sewer overflow, sudden downpour (flash flood), and/or storm-water drainage (urban floods). In Australia, the most common form of flooding is along rivers after heavy and/or prolonged 
rainfall [8]. Jonkman and Kelman [26] showed that flood damage in the United States is highest in areas near rivers, particularly in areas with deep water rivers or rivers at lower elevations. Nicholls and Tol [27] noted that the annual mean and probable maximum rainfall is other important flood characteristic to predict the potential flood damage to roads and bridge structures. However, there is strong evidence that the greater the resilience of an individual bridge or road, the lower the likely economic damage caused by floods, and that the benefits of resilience can be dramatic [5].

Godschalk [28] defined resilience as "the ultimate objective of hazard mitigation, that is, action taken to reduce or eliminate long-term risk to people and property from hazards and their effects." Other scholars have adopted and adapted this definition differently across different disciplines and currently there is no generally accepted definition. For example, Levina and Tirpak [29] proposed two key aspects for resilience: the ability of a system to withstand a disturbance without changing, implying that no damage is done; and the ability of the system to recover when damage has occurred. Further, Maguire and Cartwright [30] articulated three views of resilience: resilience as stability and resistance to change; resilience as recovery following change and return to the previous stable state; and resilience as transformation to a new and different stable state following change. Recently, Manyena et al. [31] defined resilience as the "intrinsic capacity of a system, community or society predisposed to a shock or stress to bounce forward and adapt in order to survive by changing its nonessential attributes and rebuilding itself," and again, Mojtahedi et al. [5] defined resilience as the risk reduction practices undertaken before potential disasters both to minimize the probability of the disaster occurring in the first place, as well as to enable repair and replacement during and after disasters to result in improved facilities over time. Finally, it is important to note that the concept of resilience is broader than natural disasters. Resilience also encompasses the capacity of public, private, and civic sectors to resist disruption, absorb disturbance, act effectively in a crisis, adapt to changing conditions and grow over time [32].

Park et al. [33] summarized the key challenges facing a more coherent and robust approach to resilience and risk management in the design of infrastructure which are as follows:

- A lack of comprehensive data and forecasting uncertainty both promote a focus on those aspects of risk where data does exist and the hazards are better known. As a result, very significant risk factors are ignored or discounted and the resulting risk assessment can be severely misleading.

- Current infrastructure design is based on the prevailing building codes and regulations. These codes develop and evolve slowly over time. The codes can fail to incorporate significant emergent hazards or respond effectively to new lessons from disaster events. This lag has resulted in the incremental evolution of design, rather than supporting more innovative design responses.

- The many and varied design challenges that do arise are treated as individual problems to be resolved, rather than conditions to be managed more holistically and proactively. The broad-ranging and multifaceted nature of infrastructure design warrants a comprehensive approach, but this is in direct conflict with the needs of a pragmatic decision-making process that is flexible and responsive. 
The framework set out in this study will not establish parameters for detailed engineering design, but it will address some of the challenges outlined above. Most particularly, the framework will develop an approach to the evaluation of resilience that is flexible and responsive to the different situations and circumstances in which risk-assessment decisions must be made. The additive statistical method it demonstrates is a novel approach to risk assessment more generally, but is especially suited to the complexity of resilience and risk management in the design of infrastructure. The study will focus on the resilience of bridges as pivotal components in any transport network, but given the increasing frequency and severity of extreme weather events, as critical concerns for communities from major cities through to remote rural settlements.

\section{An additive statistical model}

When seeking to analyze a complex problem comprising a range of variables, the common approach is to apply a parametric regression method. Parametric regression defines a function in which the terms comprise a finite number of unknown parameters derived from numerical data on each of the variables of interest. In the context of transport resilience and risk management, which is highly dependent on the vagaries of individual situations, the variables of interest can vary significantly between situations. In such circumstances, regression is better defined in nonparametric terms across a set of functions. Originally proposed by Friedman and Stuetzle [34], the additive model method offers a robust and simple to interpret approach to the effect analysis of multiple variables. The additive model takes the form of a familiar regression model, but builds each model from a restricted class of nonparametric regression models. Each nonparametric model uses a one-dimensional smoother to generate linear combinations of the predictor variables in an iterative fashion.

The additive modeling approach provides distinct advantages over alternative nonparametric approaches and is entirely more general than standard stepwise regression procedures [34]. The additive model approach results in a regression model, but the relationship between each variable and the response is allowed to be flexible and/or linear in nature, as indicated in the following formula:

$$
\sum_{j=1}^{n} f_{j}\left(x_{j}\right)=\sum_{j=1}^{n} \beta_{j} \times x_{j}^{n}
$$

where $f(x)$ represents a linear or nonlinear relationships between phenomena.

Based on Eq. (1), we develop an additive statistical equation for analyzing transport infrastructure flood specific to bridge risk-based resilience as follows:

$$
r=\alpha+\sum_{j=1}^{p} f_{j}\left(x_{j}\right)+\epsilon
$$

$r$ is the resilience of a bridge to a flood event, $\alpha$ is intercept, $f(x)$ is linear or nonlinear function between the response and the relevant indicator, and $\epsilon$ is the overall error of the model. 
Additive models have the strong properties of linear or nonlinear models in so far as they are in a familiar regression form and easy to interpret, but are superior in that they relax the assumption of a linear (or known nonlinear) relationship in the data. Thus, the additive model approach is not a purely nonparametric method (which is one of the potential limitations of the proposed framework), but does represent an effective compromise between flexibility and simplicity.

To begin to build an additive model the first challenge is to identify the principal components. Choice of the principal component is dependent on the range of candidate components and the availability of data. Nonparametric regression does require larger sample sizes than parametric models because the data must support the development of a model structure as well as supply the model estimates. For the purposes of this study, a representative set of four principal components is used, but the same framework and approach can be applied to an unlimited number of principal components where relevant data are available. The principal components used in this study of resilient bridges within the context of flood risks are as follows:

$x_{1}$ : likelihood of a flood event represented by the annual exceedance probability (AEP).

$x_{2}$ : scale of a flood event represented by the probable maximum precipitation (PMP).

$x_{3}$ : structural integrity of the bridge represented by the structural age of the bridge.

$x_{4}$ : mechanical properties of the soils.

$r$ : resilience of bridge.

\subsection{Annual exceedance probability (AEP)}

There are two ways of expressing the likelihood of occurrence of a flood event, annual exceedance probability (AEP) and average recurrence interval (ARI). AEP is the probability of a flood of a given or larger size occurring in any one year, usually expressed as a percentage. For example, if a peak flood discharge (PFD) of $500 \mathrm{~m}^{3} / \mathrm{s}$ has an AEP of $5 \%$, it means that there is a $5 \%$ probability (that is one-in-20 chance) of a $500 \mathrm{~m}^{3} / \mathrm{s}$ or larger event occurring in any one year. ARI is the long-term average number of years between the occurrences of a flood as big as or greater than the selected event. For example, floods with a discharge equal to or greater than the 20-year ARI flood event will occur on average once every 20 years [25].

AEP is selected in this instance, as the data is readily available in this form. The relationship between bridge resilience and AEP is then formulated as follows:

$$
y_{1}=a_{1} \times \operatorname{Ln}\left(x_{1}\right)+b_{1}
$$

where $a_{1}$ and $b_{1}$ are the constant factors. Since there is a linear relationship between $y_{1}$ and $\left(x_{1}\right)$, the possible linear regression can be determined by the following equations.

$$
a_{1}=\left[\frac{\sum_{i=1}^{n}\left(y_{i}-\bar{Y}\right) \times\left(\left(\operatorname{Ln}\left(x_{i}\right)\right)-\bar{X}\right)}{\sum_{i=1}^{n}\left(\left(\operatorname{Ln}\left(x_{i}\right)\right)-\bar{X}\right)^{2}}\right]
$$


Intercept $b_{1}=\bar{Y}-a_{1} \times \bar{X}$, where $\bar{Y}$ is the mean value of flood risk-based resilience in different cases, and $\bar{X}$ is the mean value of the AEP in different cases. Hence,

$$
\bar{Y}=\left[\frac{\sum_{i=1}^{n} y_{i}}{n}\right] \text { and } \bar{X}=\left[\frac{\sum_{i=1}^{n} L n\left(x_{i}\right)}{n}\right]
$$

\subsection{Probable maximum precipitation (PMP)}

World Meteorological Organization defined probable maximum precipitation (PMP) as “...the theoretical maximum precipitation for a given duration under modern meteorological conditions." PMP is specific to a given storm area at a particular location at a particular time of the year, with no allowance made for long-term climatic trends. The relationship between the flood risk-based resilience and PMP can be established by the following equation:

$$
y_{2}=a_{2} \times \operatorname{Ln}\left(x_{2}\right)+b_{2}
$$

where $a_{2}$ and $b_{2}$ are the constant factors. Since there is a linear relationship between $y_{2}$ and $\left(x_{2}\right)$, the possible linear regression can be determined by the following equations:

$$
a_{2}=\left[\frac{\sum_{i=1}^{n}\left(y_{i}-\bar{Y}\right)\left(\left(\operatorname{Ln}\left(x_{i}\right)\right)-\bar{X}\right)}{\sum_{i=1}^{n}\left(\left(\operatorname{Ln}\left(x_{i}\right)\right)-\bar{X}\right)^{2}}\right]
$$

Intercept $b_{2}=\bar{Y}-a_{2} \times \bar{X}$, where $\bar{Y}$ is the mean value of flood risk-based resilience in different cases, and $\bar{X}$ is the mean value of the PMP in different cases. Hence,

$$
\bar{Y}=\left[\frac{\sum_{i=1}^{n} y_{i}}{n}\right] \text { and } \bar{X}=\left[\frac{\sum_{i=1}^{n} \operatorname{Ln}\left(x_{i}\right)}{n}\right]
$$

\subsection{Structural age of the bridge}

The structural integrity of a bridge is an obvious and critical consideration in any risk assessment. Structural integrity is directly influenced by the age of the structure, but the influence is different for different construction materials. Given the rich mix of materials used in bridge construction in Australia, and especially the preponderance of heritage bridges, a mathematical relationship between bridge structure age and the resilience of the bridge against flooding is developed. The structural age of a bridge depends heavily on the structural materials used. A range of materials and combinations of material are possible. For the purposes of this framework, the materials to be considered include brick, mortar, and cast iron.

\subsubsection{Brick}

One of the first tasks undertaken by the first European settlement in Australia was to search for suitable clay for brick manufacture. This was quickly found in an area that has become the southern sector of Sydney's central business district. This was in production for about 
50 years until urban growth, and diminishing deposits meant that alternative sources had to be discovered. There is some irony in that these areas, which provided such large quantities of building material, were also those where seasonal swelling and shrinkage of foundation soils were to cause damage to low-rise buildings. One of the early problems was in attaining a sufficiently high temperature in the kilns in these early stages of the industry. It is clear that a range of quality of brick was produced and a careful inspection process would then select the best ones for higher-level work.

\subsubsection{Mortar}

Engineers' customarily first think of mortar as the component of structural concrete other than the coarse aggregate. This uses Portland cement, but the use of this type of cement mortar for the repair of heritage structures has frequently proved to be disastrous. One reason is that the low permeability of this type of mortar does not allow extrusion of fluid build-up within the main structural components, whether they are brick or stone. This means that there is a deterioration of these components even before the mortar, which is intended to be regarded as expendable and replaceable in a much shorter life span. In order to eliminate this problem, it is necessary to revert to the once-popular use of lime-based mortar-or partly so-which has a greater porosity, especially if the proportion of sand is much higher than is usual for concrete. One dictum is to aim for a permeability of mortar that matches that of the bricks. Another attribute of lime mortar is that is more elastic than Portland cement mortar which means that, under various types of stress, the mortar will yield rather than the greater strength of Portland cement mortar causing the main material to fracture, if weaker.

\subsubsection{Cast iron}

The use of blast furnaces in the reduction of iron oxides to some form of usable iron results in pig iron. This metal has a carbon content range of from 2.7 to $4.0 \%$, but includes a large proportion of impurities. Such a material would have been of practical use in those early societies capable of its production, but the arrival of the industrial age demanded a more refined and consistent product. A standard method of bringing this about was by a more cautious process of reheating in a "cupola" furnace. This resulted in iron with carbon content in the middle of the above range, but still retaining useful quantities of silicon and manganese. Tests have been carried out on cast iron used in the joint connection units in New South Wales (NSW) timber truss bridges of 100 years ago. The carbon content varied from 3.0 to $3.3 \%$ with the former material having the slightly greater strength. This traditional material is referred to as "gray" cast iron in order to distinguish it from later types with improved properties. It should be pointed out that variants of gray iron are still widely used in industry although much less in civil engineering as primary components. Gray cast iron has a compressive strength in the range of $600-700 \mathrm{MPa}$. Its other main characteristic, however, is that its tensile strength is only about one-fifth of the compressive strength. What this means is that manipulation of the second moment of area of an "I" section in the interests of the economy produces a grotesquely large tension flange both in width and in thickness. As well as being a quick identifier of the material used, this section characteristic can be put to good use in that the extra-wide bottom flanges, as in the case of floor joists, can be used as the springing for shallow brick arches 
between adjacent joists, thereby providing a floor support structure ("jack arches"). While gray cast iron has an excellent resistance to corrosion, it has a disadvantage in its brittleness. This made it difficult to cope with the high impact nature of railway loadings as early railway engineers discovered: often the hard way. As well as its attempted use in bridges, cast iron was even used for short sections of railway track rails, and the high resulting fracture rate at least had the result of encouraging the larger scale production of wrought iron and the development of rolling mills. The main success of cast iron was in its use of columns, where the stress is primarily in compression throughout. There is a consensus against the repair of cast iron by orthodox welding technique, but there are proprietary methods available, developed from technologies used for machinery castings failures. A hazard sometimes found with cast iron is graphitization, often occurring where there is immersion in or contact with salt water and where there is a reaction with the carbon streaks within the iron. An example of this took place in the 1874 cast iron piers of the Windsor Bridge near Sydney. Although the bridge is a long way upriver, the tidal cycle of the Pacific Ocean with reduced outflow below dams has gradually increased the saline content.

The following equation would be suggested to evaluate the relationship between the resilience of bridge against flood and bridge structure age. We assume that bridge structure age is highly dependent on bridge materials such as brick, mortar, and cast iron. The relationship between the flood risk-based resilient and bridge structure age can be established by the following equations:

$$
y_{3}=a_{3} \times x_{3}^{2}+b_{3} \times x_{3}+c_{3}
$$

where $a_{3}, b_{3}$, and $c_{3}$ are the constant factors. The matrix equation for quadratic regression is:

$$
\left[\begin{array}{ccc}
\sum_{i=1}^{n} x_{i}^{4} & \sum_{i=1}^{n} x_{i}^{3} & \sum_{i=1}^{n} x_{i}^{2} \\
\sum_{i=1}^{n} x_{i}^{3} & \sum_{i=1}^{n} x_{i}^{2} & \sum_{i=1}^{n} x_{i} \\
\sum_{i=1}^{n} x_{i}^{2} & \sum_{i=1}^{n} x_{i} & n
\end{array}\right] \times\left[\begin{array}{c}
a_{7} \\
b_{7} \\
c_{7}
\end{array}\right]=\left[\begin{array}{c}
\sum_{i=1}^{n} x_{i}^{2} y_{i} \\
\sum_{i=1}^{n} x_{i} y_{i} \\
\sum_{i=1}^{n} y_{i}
\end{array}\right]
$$

where $n$ is the number of data points $\left(x_{i^{\prime}}, y_{i}\right)$.

\subsection{Mechanical properties of the soils}

Determination of the mechanical properties of the soil as well as the level of the pore pressure is major aspects in the current statistical simulations. Provided that there are $n$ layers of different soils have been reported in the different suggested sites, the simulated values for both the horizontal as well as bending stresses in different layers can be calculated by the following procedure. It should be noted that a linear strain distribution was assumed across the soil section.

The suggested procedure can be used to find a relationship between the collected data and the vulnerability of the bridges. It should be interesting to investigate that there is an inverse relationship between the mechanical properties of the soils and the damage level [35]. The 
reasons for this could be due to different construction methods adopted in the past or they had been rehabilitated after the previous disaster event. However, these reasons should be further scrutinized for confirmation. The resilience of the community depends on the resilience of the bridges on rural roads, but most of the bridges are vulnerable to extreme flood events. Therefore, when classifying roads for design, it is necessary to consider the impact on the community during and after an extreme event [36]. Thus, the relationship between the flood risk-based resilient and bridge structure age can be established by the following equation:

$$
y_{3}=a_{4} \times e^{b_{4} \times x_{4}}+c_{4} \times x_{4}+d_{4}
$$

where $a_{4}, b_{4^{\prime}}, c_{4^{\prime}}$ and $d_{4}$ are the constant factors.

\subsection{Resilience of transport infrastructure}

Globally, infrastructure is recognized as a critical element for strong economies and stable communities and it facilitates society's daily activities. Infrastructure can be considered to include everything from the physical infrastructure of roads, bridges, airports, rail, water supply, telecommunications and energy services, to the social infrastructure of health care, education, banking and finance services, emergency services, and the justice system [32]. Croope [37] states "Critical infrastructure not only responds to the needs of society for the smooth daily continuation of activities, but also provides the basis on which society exists and relies." Godschalk [28] lists two reasons behind the importance of resilience which are as follows:

1. Because the vulnerability of technological, natural, and social systems cannot be anticipated, the capability to accommodate change without catastrophic failure in times of disaster is vital.

2. People and property fare better in resilient cities when struck by disasters. Fewer buildings collapse, fewer power outages occur, fewer businesses are put at risk, and fewer deaths and injuries occur.

Societies have an increasing reliance on transportation networks for their day-to-day activities. The ability of the transport system to function during adverse conditions and quickly recover to acceptable levels of service after an event is fundamental to the wellbeing of people within society. Resilience is considered the ultimate objective of hazard mitigation, that is, " action taken to reduce or eliminate long-term risk to people and property from hazards and their effects" [28].

Resilience has two main dimensions such as (i) technical and (ii) organizational. Technical dimension refers to the ability of the physical system(s) to perform to an acceptable level when subject to a hazard event [38]. In this research, we have focused on technical dimension of the resilient bridge, and therefore, we have considered four technical factors for resilient bridges such as (i) AEP, (ii) bridge structure age, (iii) mechanical properties of the soils, and (iv) PMP. 
Some scholars have applied to measure the resilience of transport infrastructure. For example, Mojtahedi et al. [5] used Cox's proportional hazards regression model to determine the rate of recovery and cumulative probability that recovery occurs for transport infrastructure across regional areas in New South Wales, Australia.

\section{Numerical example}

\subsection{Resilience of a bridge and AEP}

We have assumed that the resilience of bridge is dependent on the relationship between peak flood discharge (PFD) and annual exceedance probability (AEP). A numerical example can be introduced by the following assumed data, provided that there is a possible collected data between the PFD $\left(\mathrm{m}^{3} / \mathrm{s}\right)$ versus AEP, which has been presented in Table 1.

Thus, the following equation $y_{1}=a_{1} \times \operatorname{Ln}\left(x_{1}\right)+b_{1}$ can be represented by $y_{1}=0.045 \times \operatorname{Ln}\left(x_{1}\right)+$ 0.0233. Furthermore, based on Figure 1, it can be observed that after reaching to PFD around $500\left(\mathrm{~m}^{3} / \mathrm{s}\right)$, the recorded AEP would be converged to 0.3 which can be taken into account as a potential critical value.

A same trend to examine the mutual interaction between the PFD versus AEP has been investigated by using $t$-test. After normalizing, the respond data, which is the AEP, the $t$-test values, and distribution can be presented (Figure 2). The same conclusion can be found that after reaching to the PFD $500\left(\mathrm{~m}^{3} / \mathrm{s}\right)$, the value for the AEP would be a constant value. This can show that the resilient respond after the PFD $500\left(\mathrm{~m}^{3} / \mathrm{s}\right)$ would be slightly different from the further increments.

\subsection{Resilience of a bridge and PMP}

We have assumed that the resilience of bridge is dependent on the relationship between the size of storm area and probable maximum perception (PMP). The PMP can be a function of a given size storm area at the particular location at the particular time of the year. Provided that Table 2 presents the assumed size storm area $\left(\mathrm{km}^{2}\right)$ versus PMP, thus, the possible mathematical relationship can be $y_{2}=a_{2} \times e^{-b_{2} \times x_{2}}+c_{2} \times x_{2}+d_{2}+$.

Thus, we can have $y_{2}=-0.00766 \times e^{-0.00288 \times x_{2}}+0.000544 \times x_{2}+0.00022$. Based on Figure 3, there is a semilinear relationship between the PMP and the size storm area.

Normalized PMP values versus $t$-test distribution are also illustrated in Figure 4.

\begin{tabular}{lllllllllllll}
\hline PFD $\left(\mathbf{m}^{3} / \mathrm{s}\right)$ & $\mathbf{1 0 0}$ & $\mathbf{2 0 0}$ & $\mathbf{3 0 0}$ & $\mathbf{4 0 0}$ & $\mathbf{5 0 0}$ & $\mathbf{6 0 0}$ & $\mathbf{7 0 0}$ & $\mathbf{8 0 0}$ & $\mathbf{9 0 0}$ & $\mathbf{1 0 0 0}$ & $\mathbf{1 1 0 0}$ & $\mathbf{1 2 0 0}$ \\
\hline $\mathrm{AEP}$ & 0.23 & 0.26 & 0.27 & 0.29 & 0.30 & 0.311 & 0.32 & 0.324 & 0.329 & 0.334 & 0.338 & 0.342 \\
\hline
\end{tabular}

Table 1. Peak flood discharge (PFD) versus annual exceedance probability (AEP). 


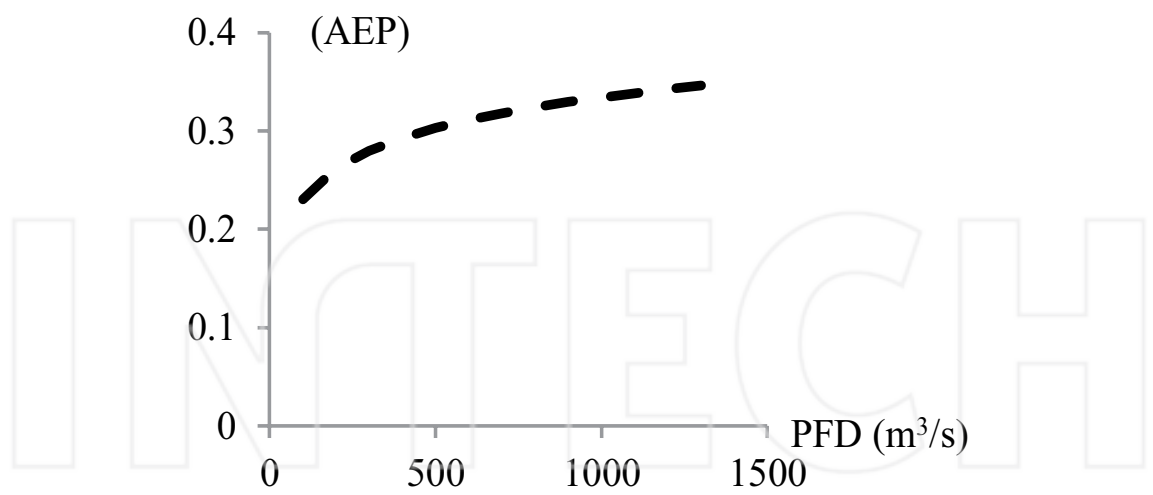

Figure 1. Peak flood discharge versus AEP.

As it can be realized in both Figures 3 and 4, the critical value of the PMP can be observed where there is size storm area over $60\left(\mathrm{~km}^{2}\right)$. This is a condition where the PMP rate is more inclined with a constant rate rather than increasing sharply. Based on the numerical assumption, after size storm area over $60\left(\mathrm{~km}^{2}\right)$ might be classified as a possible significant region/ condition.

\subsection{Resilience of a bridge and structure age}

We have assumed that the resilience of bridge is dependent to the relationship between the bridge structure age and bridge collapsing risk. At this stage, some of the critical materials that can perform as a key role on constructing heritage roads/bridges were discussed in Section 3.3. This topic is significantly important where some of the heritage link constructions might be jeopardized by the induced flood around the NSW.

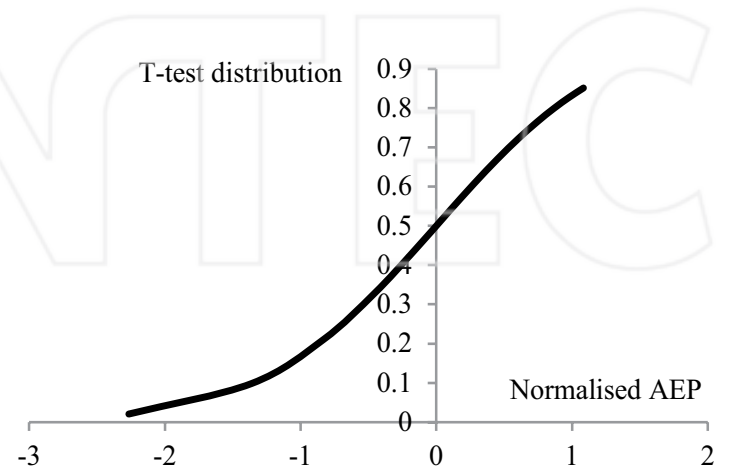

Figure 2. Normalized AEP versus $t$-test distribution values. 


\begin{tabular}{lllllllllllll}
\hline The size storm area & $\mathbf{1 0}$ & $\mathbf{2 0}$ & $\mathbf{3 0}$ & $\mathbf{4 0}$ & $\mathbf{5 0}$ & $\mathbf{6 0}$ & $\mathbf{7 0}$ & $\mathbf{8 0}$ & $\mathbf{9 0}$ & $\mathbf{1 0 0}$ & $\mathbf{1 1 0}$ & $\mathbf{1 2 0}$ \\
\hline PMP & 0.029 & 0.058 & 0.086 & 0.11 & 0.144 & 0.173 & 0.2 & 0.231 & 0.26 & 0.288 & 0.34 & 0.432 \\
\hline
\end{tabular}

Table 2. The probable maximum perception (PMP) versus the size storm area.

Table 3 presents a numerical example of the relationship between the collapsing risk response and bridge structure age where the presented age is based on the number of decades.

As the time goes by, the risk of the collapsing of the structure increases. This somehow shows the risk assessment as a function of time. Figure 5 demonstrates the collapsing risk response versus bridge structure age.

The same approach was taken into account to calculate the $t$-test distribution against the normalized collapsing risk response. Figure 6 illustrates the $t$-test distribution, where it can be found that the collapse mechanism in the simulated bridges can significantly affected after 40 years where there is a possibility of starting fatigue behavior. The relationship between the collapsing risk response and bridge structure age is a quadratic function. The possible function can be presented as $0.000788 \times x^{2}+0.00011 \times x+0.000655$.

\subsection{Resilience of a bridge and mechanical properties}

We have assumed that the resilience of bridge is dependent to the relationship between the strength of the soil (MPa) and bridge safety. Table 4 presents a numerical example of the relationship between the bridge safety factor and strength of the soil (MPa).

Figure 7 presents the same trend where it can demonstrate strength of the soil versus the risk safety factor. As it can be found, the factor of safety is converged by the mean value of the strength of the soil and reached to $2 \mathrm{MPa}$.

Besides, Figure 8 illustrates the normalized factor of safety versus $t$-test distribution.

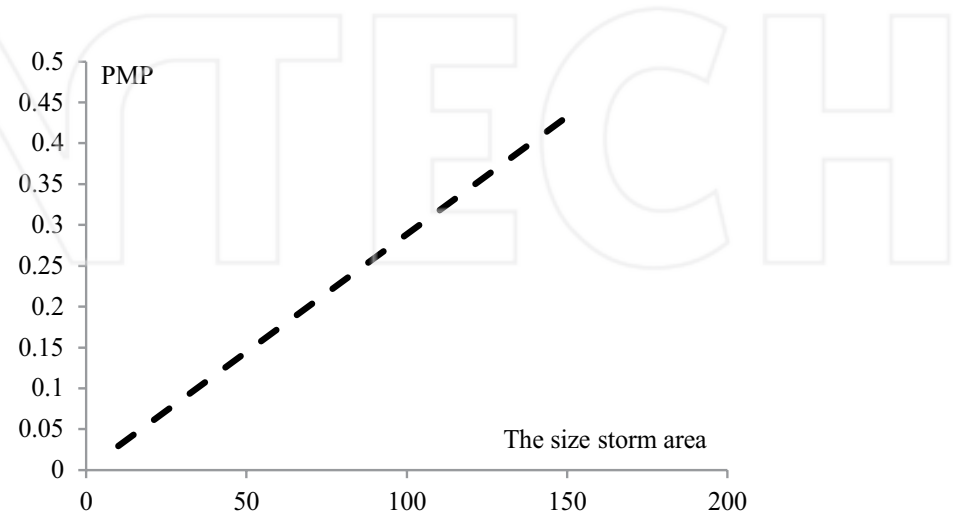

Figure 3. A semilinear relationship between the probable maximum perception (PMP) and the size storm area. 


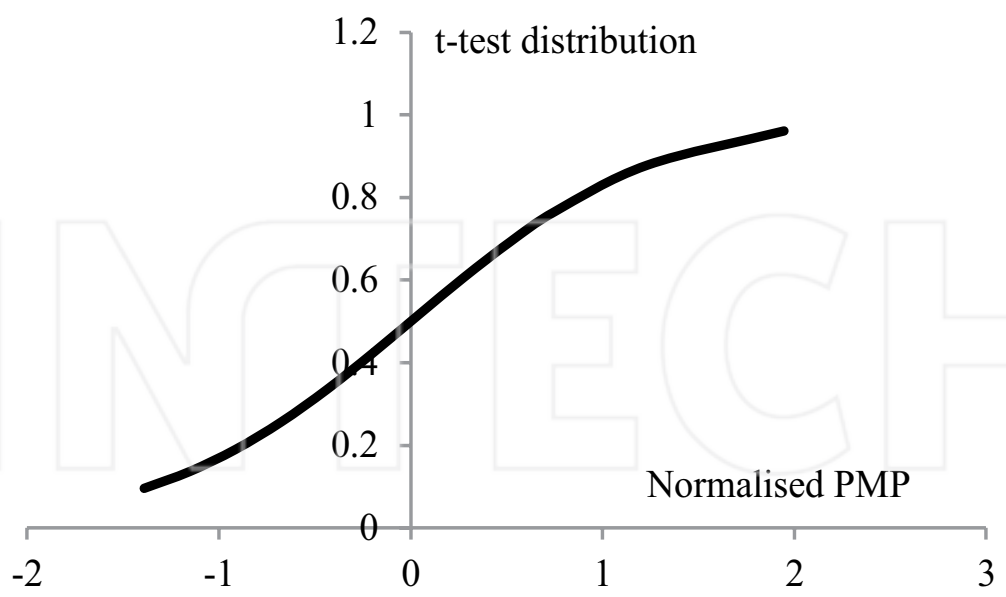

Figure 4. A normalized PMP values versus $t$-test distribution.

\begin{tabular}{lllllllllll}
\hline $\begin{array}{l}\text { Bridge structure } \\
\text { age (decades) }\end{array}$ & $\mathbf{1}$ & $\mathbf{2}$ & $\mathbf{3}$ & $\mathbf{4}$ & $\mathbf{5}$ & $\mathbf{6}$ & $\mathbf{7}$ & $\mathbf{8}$ & $\mathbf{9}$ & $\mathbf{1 0}$ \\
\hline $\begin{array}{l}\text { Collapsing risk } \\
\text { respond }\end{array}$ & 0.0001 & 0.003 & 0.007 & 0.013 & 0.02 & 0.03 & 0.04 & 0.05 & 0.06 & 0.08 \\
\hline
\end{tabular}

Table 3. The Collapsing risk response versus bridge structure age.

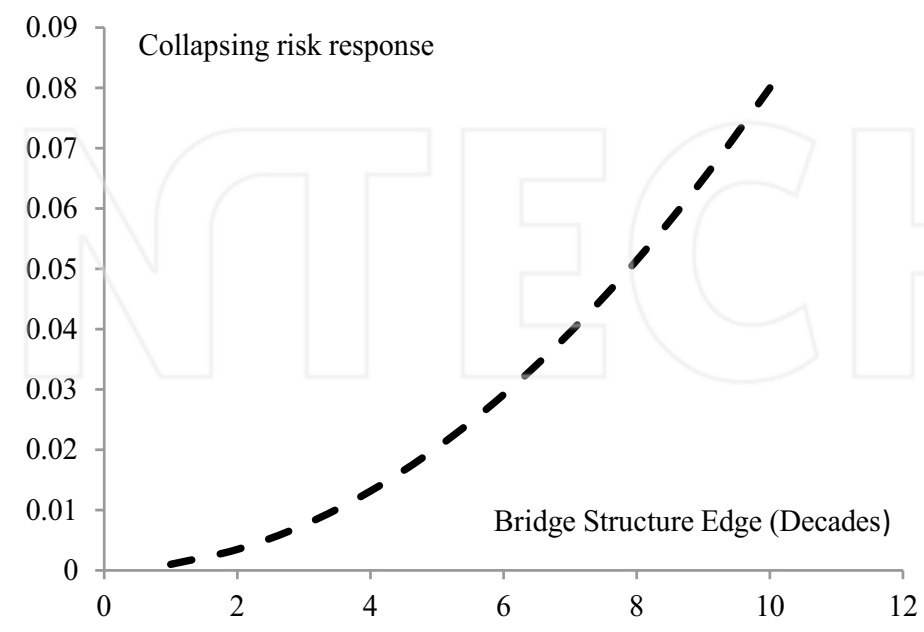

Figure 5. Collapsing risk response versus bridge structure age. 


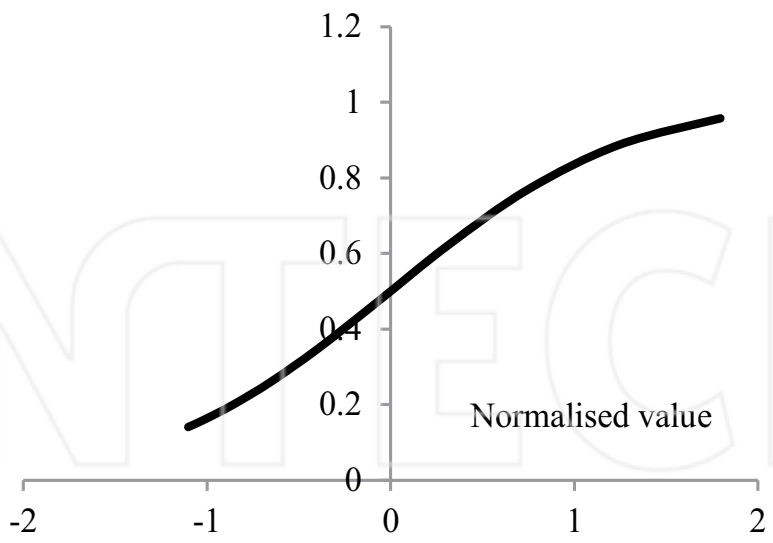

Figure 6 . The $t$-test distribution against the normalized collapsing risk response.

\begin{tabular}{ll}
\hline Strength of the soil (MPa) & Factor of bridge safety \\
\hline 0.1 & 1.44 \\
0.2 & 1.56 \\
0.3 & 1.72 \\
0.4 & 1.78 \\
0.5 & 1.80 \\
0.6 & 1.78 \\
0.7 & 1.76 \\
0.8 & 1.73 \\
0.9 & 1.74 \\
1 & 1.72 \\
\hline
\end{tabular}

Table 4. Strength of the soil versus the risk safety factor.

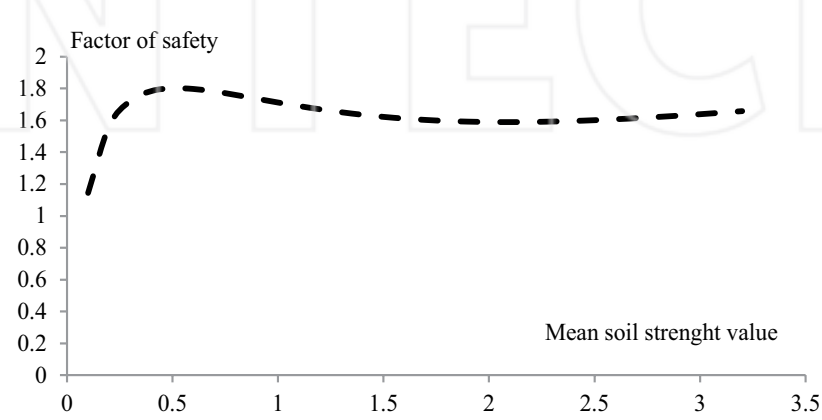

Figure 7. Strength of the soil versus the risk safety factor. 


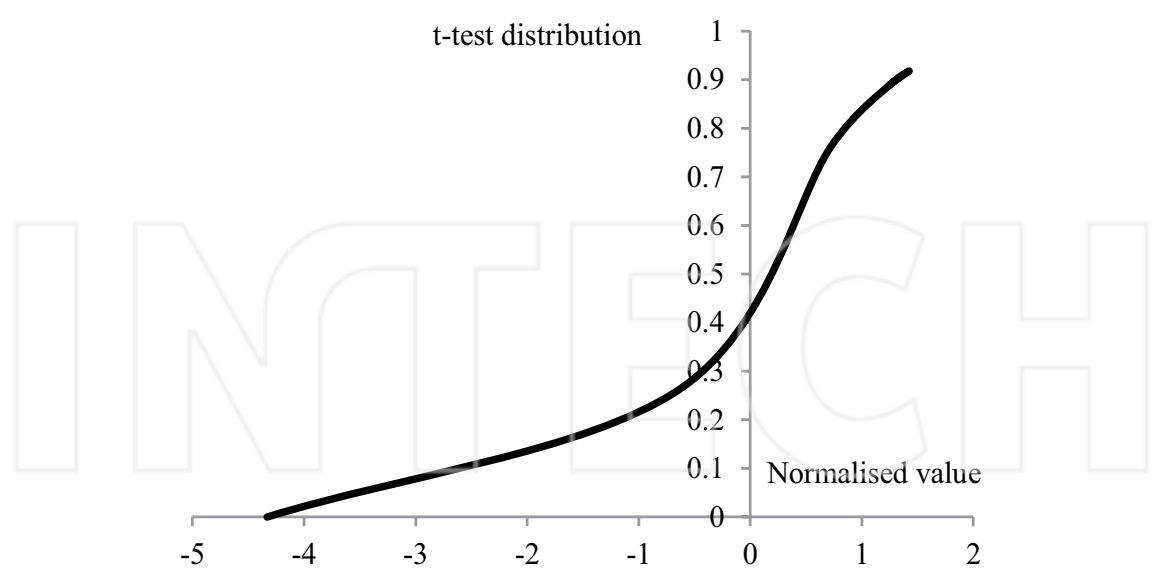

Figure 8. The normalized factor of safety versus $t$-test distribution.

\subsection{Additive combination of factors for flood risk-based resilient}

Provided that there is a mutual interaction relationship between the two particular indicators, for example, between $x_{1}$ : AEP and $x_{2}$ : PMP as well as the major response where it would be the resilient of bridge, the following equation can be considered to evaluate and determine the critical zones, $\left(\frac{x_{1}}{R}\right)^{m}+\left(\frac{x_{2}}{R}\right)^{n}=k_{1}$, where $m, n \geq 2$ and $k_{1}$ is a constant value.

The same trend can be extended to the interaction between the $x_{3}$ : bridge structure age and $x_{4}$ : mechanical properties of the soils as the major indicators and resilient of bridge as the response. Thus, $\left(\frac{x_{3}}{R}\right)^{p}+\left(\frac{x_{4}}{R}\right)^{q}=k_{2}$, where $p, q \geq 2$ and $k_{2}$ is a constant value. Figures 9 and 10 present the relevant interactions of the different arrangements explained.

Provided that we assume $x_{2}$ is more critical than $x_{1}$, then the nonresilient region would be trended to the horizontal access in Figure 9. This condition can be shifted if the assumed condition between $x_{1}$ and $x_{2}$ is switched. The same assumption can be extended in Figure 10 where it was assumed that $x_{4}$ is more critical than $x_{3}$. The major limitation of the suggested model is how to define the critical/noncritical condition in the unknown region where it is situated between the resilient and nonresilient regions.

An inclination can be considered to have a combination of all of the indicators $\left(x_{1}, x_{2}, x_{3}, x_{4}\right)$ where they are interacted with the resilience of the transport infrastructure $R$ as a major response. Thus, we can have, $\left(\frac{x_{1}}{R}\right)^{m}+\left(\frac{x_{2}}{R}\right)^{n}+\left(\frac{x_{3}}{R}\right)^{p}+\left(\frac{x_{4}}{R}\right)^{q}=k_{1}+k_{2^{\prime}}$ where $m, n, p, q \geq 2$ and $k_{1}$ and $k_{2}$ are constants.

The suggested interaction diagrams as well as the overall combination of the available indicators can graphically help to determine the resilient and nonresilient (as a critical condition) regions in the presented graphs. It can also provide a reliable tool for urban/regional planner as well as the major decision makers to make a more reliable outcome schedule/scope for the communities. The suggested methods can be significantly improved by having access to the different regional/community data. Also, the suggested method should be unbiasedly tested 


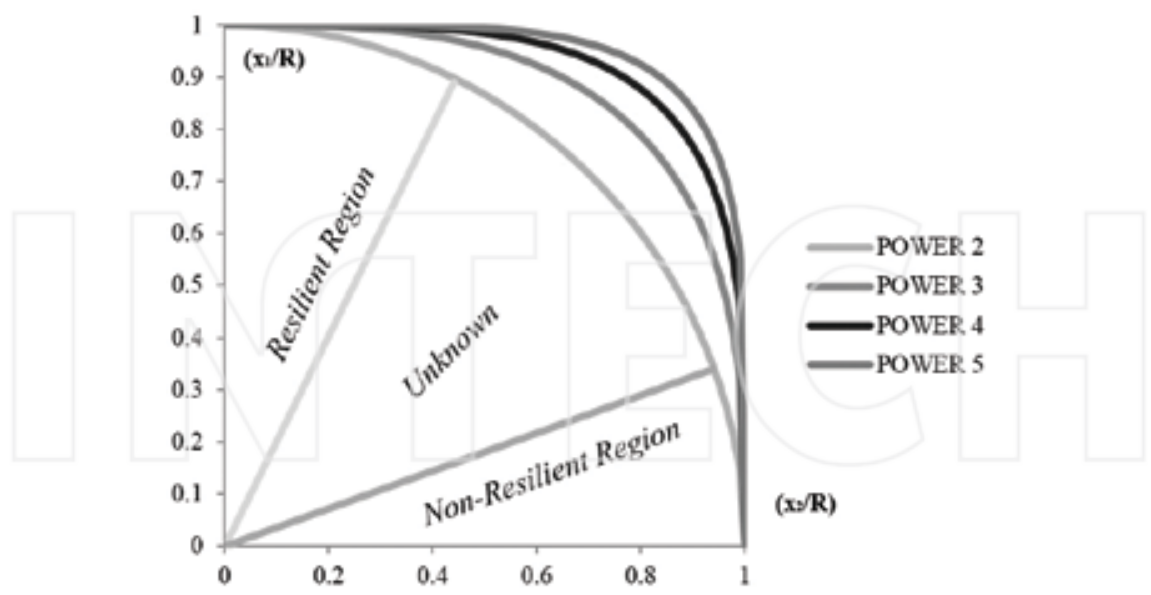

Figure 9. The interaction between $x_{1}$ and $x_{2}$ and $R$ with the different applied powers in $m$ and $n$.

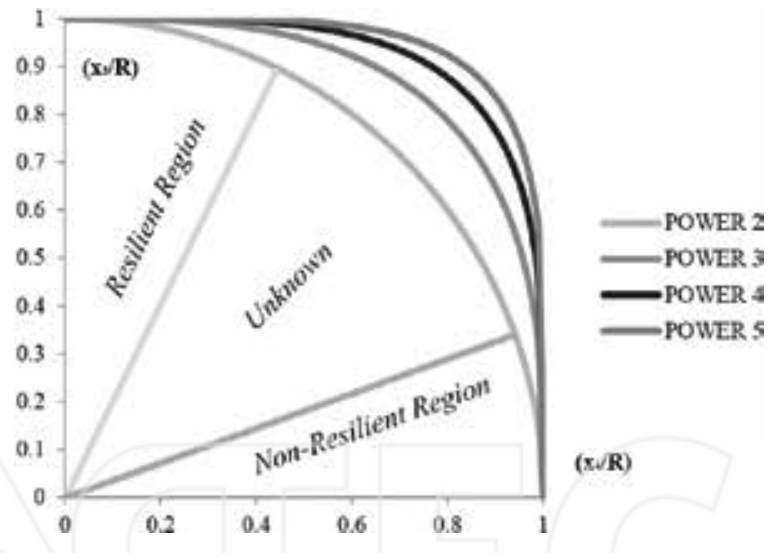

Figure 10. The interaction between $x_{3}$ and $x_{4}$ and $R$ with the different applied powers in $p$ and $q$.

in different councils in order to validate the suggested hypothesis. It can provide a reliable tool for urban/regional planers.

\section{Conclusions and recommendations}

Australia's transport infrastructure has long been exposed to floods. Some infrastructure is no longer fit for purpose, with design standards failing to keep pace with the resilience needs of a changing world. In addition, the meteorological factors of the specific region might exacerbate the vulnerability of transport infrastructure to flood events. Relationships between 
meteorological factors and transport infrastructure technical factors have never been conceptualized into integrated mathematical models for analyzing risks and measuring the resilience of transport infrastructure to flood events. Here, we used a systems approach to identify critical resilience factors for resilience measurement in transport infrastructure in Australia. The research methodology in this study covered a systematic literature review, mathematical model development, and numerical example conducted by simulation. We used additive statistical model for developing risk-based resilient decision-making system to predict the resilience of bridges. The additive model allows identifying significant predicting variables and their impacts on infrastructure planning and flood risk management. The main novelty of this research is to develop risk-based resilient equations, which would be included in both linear and nonlinear multiple regression. The equations adopt a design methods framework and reference the probability and known impact of previous floods along with the probability and aggregated costs of bridges repair work to estimate an optimum resource expenditure balance between flood risk reduction and flood disaster management. The results addressed transformations toward future resilience requires an integrated approach that allows expression of multiple perspectives on the problem, and supports an adaptive planning approach that is open for experimentation and learning. Infrastructure planners, operators, and regulators need a simple and robust method to evaluate flood risks to better manage the flood risk mitigation, preparedness, response, and recovery of our roads and bridges to extreme flood events.

This research focused on flooding as well as the effect of the natural disaster, but results can be extended to other forms of hazard communication and perception. Quantitative and qualitative analyses supported the adoption of a broad conceptualization of risk communication in both theory and practice. Additionally, the possible relationships of regulated space to communication, perception, and behavior identified in this research are relevant in other contexts where specific areas are politically delineated as hazardous. These results also contribute to more general debates over public understanding of probability and uncertainty as well as those regarding the connections between understanding, attitude, and behavior. This study confirmed that metrological characteristics such as AEP and PMP and bridge conditions such as age and mechanical properties of materials have a substantial impact on the resilience of the Australian transport infrastructure, particularly bridges located on main roads.

A number of more general recommendations for effective flood risk management relevant to transport infrastructure in Australia emerge from this study:

- Greater control of the zoning and use of land in areas prone to high AEP and PMP are required to reduce the need to construct roads and bridges in those areas.

- Upgrading bridges with brick and mortar to cast iron bridges and more resilient bridges will make them less vulnerable to flood damage and significantly reduce the costs of flooding.

- Paying significant attention to the design phase of a bridge and more comprehensive flood risk management approach to incorporate more mitigation strategies will better address the full range of causal factors.

- The fact that Australian aged bridges are not as vulnerable to floods as new bridges calls for a changed funding model for bridge maintenance and upgrades. 
The suggested methods can be significantly improved by having access to the different regional/community data. Also, the suggested method should be unbiasedly tested in different councils in order to validate the suggested hypothesis. It can provide a reliable tool for urban/ regional planers. Further research is needed to assess the broader flood risk variables and flood risk management capabilities particular to more vulnerable regions and relevant jurisdictions.

\section{Acknowledgements}

This research was supported by an Early Career Research (ECR) grant at the Faculty of Built Environment at the University of New South Wales (UNSW), Australia (SIR30/PS41970).

\section{Author details}

Mohammad Mojtahedi $^{1 *}$, Sidney Newton ${ }^{1}$ and Faham Tahmasebinia ${ }^{2}$

*Address all correspondence to: m.mojtahedi@unsw.edu.au

1 Faculty of Built Environment, University of New South Wales, Sydney, Australia

2 School of Mining Engineering, University of New South Wales Sydney, Australia

\section{References}

[1] Guha-Sapir D, Vos F, Below R, Ponserre S. Annual disaster statistical review 2011: the numbers and trends. Centre for Research on the Epidemiology of Disasters (CRED); 2012.

[2] Setunge S, Lokuge W, Mohseni H, Karunasena W. Vulnerability of road bridge infrastructure under extreme flood events. In Proceedings of AFAC \& Bushfire \& Natural Hazards CRC Conference; 5-7 September 2014; University of Southern Queensland.

[3] Field CB, editor. Managing the risks of extreme events and disasters to advance climate change adaptation: special report of the intergovernmental panel on climate change. Cambridge University Press; 2012. P. 151-187.

[4] Blong R. Residential building damage and natural perils: Australian examples and issues. Building Research \& Information. 2004;32:37-41

[5] Mojtahedi M, Newton S, Von Meding J. Predicting the resilience of transport infrastructure to a natural disaster using Cox's proportional hazards regression model. Natural Hazards. 2017;85(2):1119-1133

[6] Pritchard R. 2011 to 2012 Queensland floods and cyclone events: Lessons learnt for bridge transport infrastructure. Australian Journal of Structural Engineering. 2013;14(2): $167-176$ 
[7] Meyer MD. Design Standards for US Transportation Infrastructure: The Implications of Climate Change. Washington, DC: Transportation Research Board

[8] BOM. Bureau of Meteorology, Annual Report 2009-10. 2010

[9] Wright L, et al. Estimated effects of climate change on flood vulnerability of US bridges. Mitigation and Adaptation Strategies for Global Change. 2012;17(8):939-955

[10] AGO. Climate Change Impacts and Risk Management. Canberra, Australia: Australian Greenhouse Office, Department of Environment and Herritage; 2006

[11] Mohseni H, Tran H, Setunge S. In: Bittencourt T, Frangopol D, Beck A, editors. Optimisation of inspection and maintenance activities for bridge components: In: Maintenance, Monitoring, Safety, Risk and Resilience of Bridges and Bridge Networks. CRC Press; 2016. pp. 199-199

[12] Aflatooni $M$, et al. Synthetic rating system for railway bridge management. Journal of Civil Structural Health Monitoring. 2013;3(2):81-91

[13] Laman JA, Guyer RC. Condition assessment of short-line railroad bridges in Pennsylvania. Pennsylvania: The Thomas D. Larson Pennsylvania Transportation Institute. The Pennsylvania State University; 2010.

[14] Sohn J. Evaluating the significance of highway network links under the flood damage: An accessibility approach. Transportation Research Part A: Policy and Practice. 2006;40:491-506

[15] Alexander D. The study of natural disasters, 1977-97: Some reflections on a changing field of knowledge. Disasters. 1997;21(4):284-304

[16] EM-DAT. The OFDA/CRED International Disaster Database. Brussels: Université Catholique de Louvain; 2004

[17] Mojtahedi SMH, Oo B-L. Development of an index to measure stakeholder approaches toward disasters in the built environment. Procedia Economics and Finance. 2014;18: 95-102

[18] UNISDR. Global Assessment Report on Disaster Risk Reduction: Revealing Risk, Redefining Development. Geneva, Switzerland: United Nations International Strategy for Disaster Reduction; 2011

[19] Leroy SA. From natural hazard to environmental catastrophe: Past and present. Quaternary International. 2006;158(1):4-12

[20] Ho MC, et al. How do disaster characteristics influence risk perception? Risk Analysis. 2008;28(3):635-643

[21] Merz B, et al. Estimation uncertainty of direct monetary flood damage to buildings. Natural Hazards and Earth System Sciences. 2004;4:153-163

[22] Middelmann-Fernandes M. Flood damage estimation beyond stage-damage functions: An Australian example. Journal of Flood Risk Management. 2010;3(1):88-96

[23] Balica SF, Wright NG, Meulen F. A flood vulnerability index for coastal cities and its use in assessing climate change impacts. Natural Hazards. 2012;64:73-105 
[24] Lamond J, et al. Flood Hazards: Impacts and Responses for the Built Environment. Boca Raton: CRC Press; 2012

[25] OEH. OEH 2005. Floodplain Development Manual: The Management of Flood Liable Land. NSW, Australia: Department of Natural Resources; 2005

[26] Jonkman SN, Kelman I. An analysis of the causes and circumstances of flood disaster deaths. Disasters. 2005;29:75-97

[27] Nicholls RJ, Tol RSJ. Impacts and responses to sea-level rise: A global analysis of the SRES scenarios over the twenty-first century. Philosophical transactions. Series A, Mathematical, Physical, and Engineering Sciences. 2006;364:1073-1095

[28] Godschalk DR. Urban hazard mitigation: Creating resilient cities. Natural Hazards Review. 2003;4(3):136-143

[29] Levina E, Tirpak D. Adaptation to Climate Change: Key Terms, Organization for Economic Co-Operation and Development, International Energy Agency (OECD); 2006. p. 2011-2015

[30] Maguire B, Cartwright S. Assessing a Community's Capacity to Manage Change: A Resilience Approach to Social Assessment. Canberra: Bureau of Rural Sciences; 2008

[31] Manyena B, et al. Disaster resilience: A bounce back or bounce forward ability? Local Environment: The International Journal of Justice and Sustainability. 2011;16(5):417-424

[32] Hughes J, Healy K. Measuring the resilience of transport infrastructure. Technical Report Research Report 546. Washington, DC: Transportation Research Board, the National Academies, 2014.

[33] Park J, et al. Integrating risk and resilience approaches to catastrophe management in engineering systems. Risk Analysis. 2013;33(3):356-367

[34] Friedman JH, Stuetzle W. Projection pursuit regression. Journal of the American statistical Association. 1981;76(376):817-823

[35] Lebbe MFK, et al. Failure mechanisms of bridge infrastructure in an extreme flood event. In: Proceedings of the First International Conference on Infrastructure Failures and Consequences; 16-20 Jul 2014; Melbourne, Australia. 2014; RMIT Publishing; p. 124-132.

[36] Lokuge W, Setunge S. Evaluating disaster resilience of bridge infrastructure when exposed to extreme natural events. Proceedings of the 3rd International Conference on Building Resilience; 17-19 Sep 2013; Heritance Ahungalla, Sri Lanka. 2013; University of Salford, Centre for Disaster Resilience; pp. 1-12

[37] Croope SV. Managing Critical Civil Infrastructure Systems: Improving Resilience to Disasters. University of Delaware; ProQuest Dissertations Publishing; 2010. 150 p.

[38] Bruneau M, et al. A framework to quantitatively assess and enhance the seismic resilience of communities. Earthquake Spectra. 2003;19(4):733-752 